\title{
Disruption of timing behavior following amphetamine withdrawal
}

\author{
ROBERT J. CAREY \\ VA Hospital and Syracuse Psychiatric Hospital, Syracuse, New York 13210
}

\begin{abstract}
The effect of a $1-\mathrm{mg} / \mathrm{kg}$ dose of d-amphetamine on the acquisition of a temporal discrimination occasioned by the reinforcement contingencies of a DRL 22-sec schedule was investigated. After $19 \mathrm{DRL}$ sessions under amphetamine, a temporal discrimination appropriate to the DRL contingencies was developed. On the 20th DRL session, saline rather than amphetamine was administered and a disruption of the temporal discrimination occurred. A saline control group given amphetamine on the 20 th session also demonstrated a disruption in their temporal response pattern.
\end{abstract}

It is well established (Kelleher \& Coats, 1961; Laties \& Weiss, 1966) that .5- and $1.0-\mathrm{mg} / \mathrm{kg}$ doses of amphetamine disrupt temporal patterns of responding generated by the reinforcement contingencies of fixed interval (FI) and differential reinforcement of low rates of responding (DRL) schedules of reinforcement. In evaluating the effects of amphetamine on learned behavior, however, it is well recognized (Lal, 1969; Overton, 1969) that there is an incomplete transfer of learning from a nondrug state to an amphetamine state, and vice versa. This "state-dependent" consideration would appear germane to understanding the effects of amphetamine on temporal response patterns generated by FI and DRL schedules of reinforcement, because the development of a timing behavior by the reinforcement contingencies of these schedules is a learning process (Carey, 1967). The alteration in responding observed when an animal with a well-trained temporal response pattern is given amphetamine, then, may be in part the result of the incomplete transfer of learning from the nondrug to the amphetamine state. This state-dependent consideration suggests that if an animal was exposed to the reinforcement contingencies of a FI or DRL schedule only while under the influence of amphetamine, a similar disruption of the temporal response pattern might also be observed if the animal was subsequently tested under the nondrug condition. The present study evaluates this possibility with regard to a differential reinforcement of low rate (DRL) schedule of reinforcement.

\section{METHOD}

\section{Subjects}

Ten naive male Sprague-Dawley rats, $400-500 \mathrm{~g}$ in weight at the start of the experiment, were used.

\section{Apparatus}

Operant responding for water reinforcement was studied in four operant chambers housed individually in sound-insulated enclosures. Each chamber contained a single 1-1/8 x 3/8 in. lever, which projected $1 \frac{1}{4}$ in. into the chamber. The lever was mounted $2 \frac{1}{4} \mathrm{in}$. above the chamber floor and required a $15-\mathrm{g}$ force $(1 / 8$ in. displacement) to activate an attached microswitch. Water reinforcement was delivered by a solenoid assembly, which allowed unlimited access to a .05-cc dipper cup. Each chamber compartment was illuminated during the test period by a $24-\mathrm{V}$ dc miniature lamp bulb mounted at the top center of the side panel. White noise was broadcast continuously into each chamber to attenuate external sounds. Switching circuits with timers and digital counters automatically programmed reinforcement, recorded responses, and controlled session durations.

\section{Procedure}

All rats were restricted to access to water for 30 min per day and initially trained to leverpress in enclosed operant chambers for $.05 \mathrm{cc}$ of water delivered on a continuous reinforcement schedule (CRF). The training criterion used was that the rat emit 50 lever responses within $30 \mathrm{~min}$ on a given daily session. Upon reaching criterion, the rats were divided into two groups of five rats each and given $38 \mathrm{DRL}$ sessions lasting $45 \mathrm{~min}$ per day with $.05 \mathrm{cc}$ of water reinforcement available on a DRL 22-sec unlimited hold schedule. One group received a subcutaneous injection of $1 \mathrm{mg} / \mathrm{kg}$ of d-amphetamine sulfate dissolved in a .9\% saline solution to a concentration of $1 \mathrm{mg} \mathrm{d}$-amphetamine per cc $15 \mathrm{~min}$ before the first 19 sessions and $1 \mathrm{cc} / \mathrm{kg}$ of $.9 \%$ saline solution $15 \mathrm{~min}$ before the start of the last 19 sessions. The second group received a $1-\mathrm{cc} / \mathrm{kg}$ injection of $.9 \%$ saline $15 \mathrm{~min}$ before Sessions 1-19 and $1 \mathrm{mg} / \mathrm{kg}$ d-amphetamine before the last 19 sessions. A $1-\mathrm{mg} / \mathrm{kg}$ dose of d-amphetamine was used because this dose level had been shown to markedly disrupt performance of rats well trained on a DRL 17.5-sec schedule (Schuster \& Zimmerman, 1961). There were four DRL sessions per week. In addition, 1 day each week for 8 weeks, both groups were tested for their spontaneous activity level for a $45-\mathrm{min}$ period in photobeam activity cages. Fifteen minutes prior to each activity test, the groups were given the same injection that they had received prior to their DRL sessions that particular week. The activity measures were obtained in order to have an independent measure of the behavioral effect of the $1-\mathrm{mg} / \mathrm{kg}$ dose of amphetamine and to check on the possible development of tolerance to the d-amphetamine.

In addition to response rate, DRL performance was evaluated by recording nonreinforced interresponse times (IRTs) (Reynolds, 1968) in 11 class intervals of $2 \mathrm{sec}$ duration from 0 to $22 \mathrm{sec}$. The IRT distribution generated by each group was analyzed statistically with the two-way analysis of variance method in terms of the conditional probability of IRTs (IRTs per opportunity) that occurred in each of the 112 -sec class intervals. Body weight and water intake were recorded daily as checks for possible untoward drug side effects. 
Table 1

Mean Number of Responses Emitted Per Minute Under the DRL 22-Sec Schedule on Sessions 1, 18, 19, 20, and 21

\begin{tabular}{|c|c|c|c|c|c|c|}
\hline \multirow{3}{*}{$\begin{array}{c}\text { DRL } \\
\text { Session }\end{array}$} & \multicolumn{3}{|c|}{ Group 1} & \multicolumn{3}{|c|}{ Group 2} \\
\hline & \multirow[b]{2}{*}{ Treatment } & \multicolumn{2}{|c|}{ Rate } & \multirow[b]{2}{*}{ Treatment } & \multicolumn{2}{|c|}{ Rate } \\
\hline & & Mean & SD & & Mean & SD \\
\hline $\begin{array}{r}1 \\
18 \\
19\end{array}$ & $\begin{array}{l}\text { Amphetamine } \\
\text { Amphetamine } \\
\text { Amphetamine }\end{array}$ & $\begin{array}{l}8.7 \\
4.9 \\
5.1\end{array}$ & $\begin{array}{c}4.0 \\
1.0 \\
.96\end{array}$ & $\begin{array}{l}\text { Saline } \\
\text { Saline } \\
\text { Saline }\end{array}$ & $\begin{array}{l}6.3 \\
5.5 \\
5.1\end{array}$ & $\begin{array}{l}0.7 \\
1.2 \\
1.0\end{array}$ \\
\hline $\begin{array}{l}20 \\
21\end{array}$ & $\begin{array}{l}\text { Saline } \\
\text { Saline }\end{array}$ & $\begin{array}{l}6.2 \\
6.5\end{array}$ & $\begin{array}{l}1.1 \\
1.1\end{array}$ & $\begin{array}{l}\text { Amphetamine } \\
\text { Amphetamine }\end{array}$ & $\begin{array}{l}7.9 \\
6.9\end{array}$ & $\begin{array}{l}2.4 \\
2.3\end{array}$ \\
\hline
\end{tabular}

\section{RESULTS}

As expected, amphetamine treatment increased responding but decreased reinforcements obtained on the DRL schedule. Of particular relevance to this study are the changes in response rates when drug treatments for the two groups were switched on Session 20. Table 1 presents the mean response rates on the 1 st, 18 th, 19th, 20 th, and 21 st sessions. When the drug treatment was switched on Session 20 either from amphetamine to saline (A-S) or from saline to amphetamine (S-A), an increase in response rate did occur. An increase in response rate from the last two sessions before the switch (18 and 19) to the first two sessions after the switch (20 and 21) occurred for each animal in both groups. Thus, administration of saline to an animal trained under amphetamine can facilitate responding. The close similarity in response rate between Groups 1 and 2 on Sessions 1 and 20 indicates that the switching procedure altered the animals' performances in the direction of that obtained at the start of DRL training. A similar type of result is evident in Fig. 1 for the temporal pattern of responding generated by the DRL schedule. As can be seen in Fig. 1, from Session 1 to Session 19, both the saline and amphetamine groups

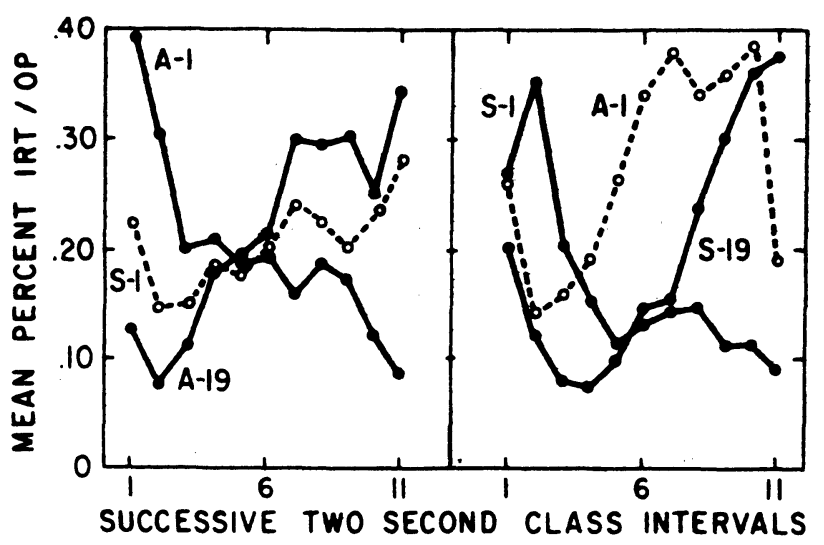

Fig. 1. Mean interresponse times per opportunity (IRTs per op) for amphetamine and saline groups on Sessions 1 and 19 before the switch and on Session 20 after the switch in drug treatment. developed the characteristic IRT pattern appropriate to prolonged exposure to DRL reinforcement contingencies. However, on Session 20, when ampehtamine and saline treatments were switched, a marked disruption in the IRT distributions occurred for both the A-S and S-A groups. This disruption in "timing" behavior, as with the changes observed in response and reinforcement rates, can also be viewed as an alteration in performance in the direction of that obtained at the start of testing. Since the IRT shifts were only directional, it seems possible to infer a partial symmetrical transfer between the amphetamine and saline treatments for this particular dose level of amphetamine.

In Fig. 1, it is also important to point out that the development of a temporal discrimination from Session 1 to Session 19 for the amphetamine group, followed by the partial breakdown of this discrimination when this group was switched to saline, indicates that amphetamine-dependent "timing" behavior was generated. However, as can be seen in Fig. 2, certain stable characteristic effects of amphetamine were evident in the distribution of IRTs generated by this DRL schedule. Figure 2 presents a more detailed analysis made of the DRL performance by examining the change in the IRTs per opportunity (IRTs per op) for each 2-sec class interval across the $38 \mathrm{DRL}$ sessions.

Figure 2 shows that amphetamine resulted in certain stable modifications in the IRT per op distributions regardless of the point in training at which the amphetamine was administered. Statistical comparison of the IRTs per op for the last five sessions (15-19) before the switch and the last five sessions after the switch (34-38) revealed several significant differences. For Sessions 15-19, the amphetamine group had significantly fewer $(\mathrm{F}=6.7, \mathrm{df}=1,8, \mathrm{p}<.05)$ IRTs per op in the 0-2-sec class interval, but significantly more in the 6-8 $(\mathrm{F}=10.1, \mathrm{df}=1,8, \mathrm{p}<.05), 8-10(\mathrm{~F}=22.9, \mathrm{df}$ $=1,8, \mathrm{p}<.01), 10-12(\mathrm{~F}=26.2, \mathrm{df}=1,8, \mathrm{p}<.01)$, $12-14(\mathrm{~F}=6.6, \mathrm{df}=1,8, \mathrm{p}<.05)$. After the switch, a similar pattern of differences was obtained for the amphetamine-treated group. Overall, under the influence of amphetamine, the rats were able to reduce short IRTs $(0-4 \mathrm{sec})$ and increase the long IRTs $(16-22 \mathrm{sec})$ as effectively as when not under the influence of 


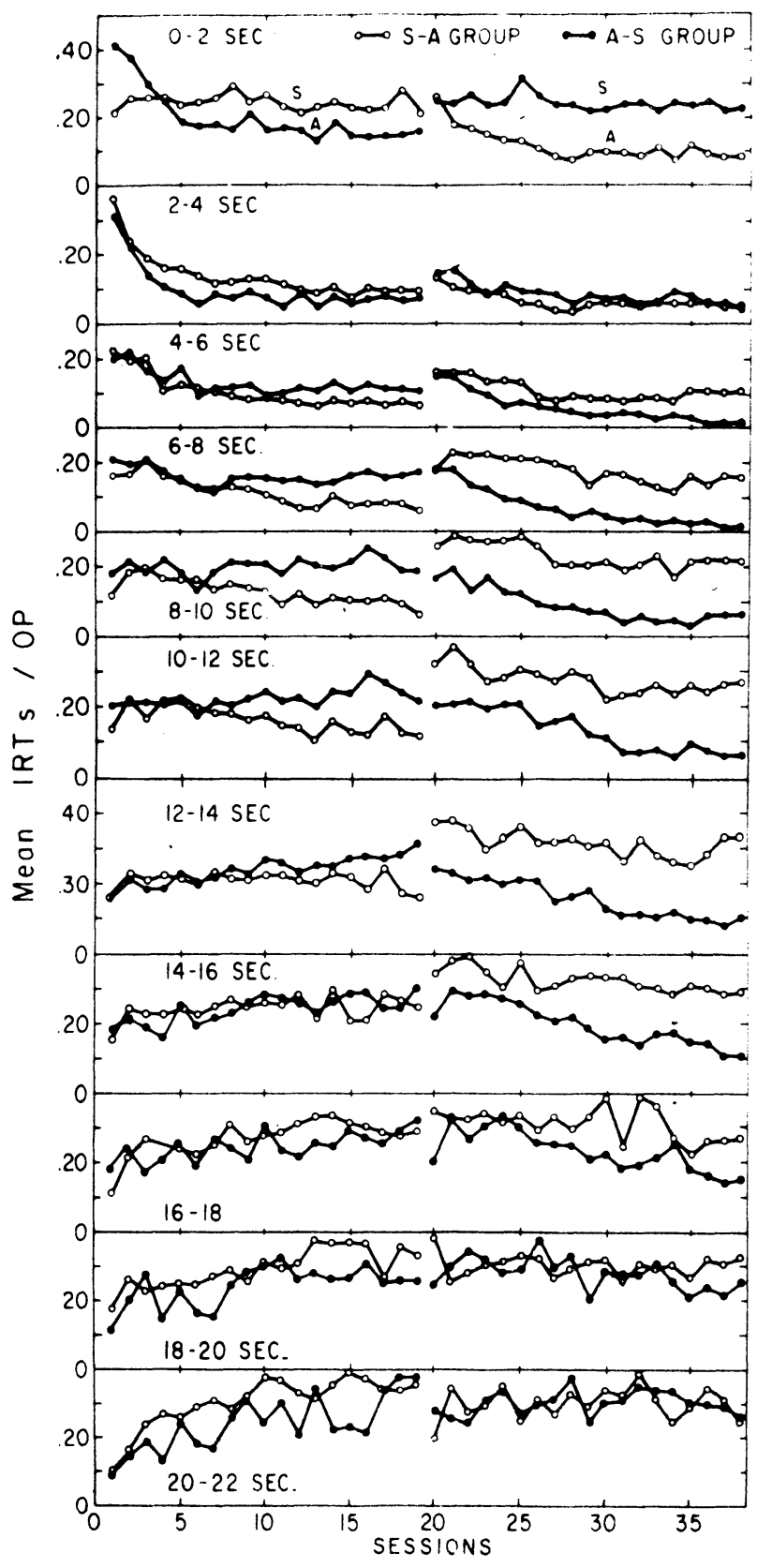

Fig. 2. Mean percentage of interresponse times per opportunity (IRTs per op) emitted in each 2-sec class interval under the $S$ (saline) and $A$ (amphetamine) treatments. amphetamine. The effect of the amphetamine on DRL performance appeared as a higher frequency of emission of the middle-duration IRTs $(6-16 \mathrm{sec})$. Translating these differences in IRT per op distributions into a temporal discrimination or timing framework, the amphetamine would then appear to have the effect of flattening the temporal gradient. This flatter gradient indicates a less accurate temporal discrimination.

The activity results are presented in Table 2 . Two results of particular importance obtained with this measure were (a) the absence of any indication of tolerance to the amphetamine, and (b) the similarity in the magnitude of the effect of the amphetamine in both groups.

\section{DISCUSSION}

The usual disruptive effect of amphetamine on the typical response patterns generated by a DRL schedule was once again replicated in this experiment. More important, though, were results in agreement with the state-dependent prediction. Specifically, under amphetamine, a reduction in response rate and the development of a temporal pattern of responding appropriate to prolonged exposure to the reinforcement contingencies of the DRL schedule was found. In addition, when amphetamine was subsequently not administered, the DRL response rate increased and the temporal distribution of responding was disrupted. A similar pattern of results was obtained when amphetamine was given to animals trained without amphetamine. These results suggest that the state-dependent properties of amphetamine may be a significant factor for some of the rate-dependent effects of amphetamine on steady-state response patterns generated by reinforcement schedules.

A state-dependent analysis, however, gives but a partial explanation for the effects of amphetamine on operant responding generated by the reinforcement contingencies of the DRL schedules. First of all, amphetamine did affect the DRL response and reinforcement rate, even when given at the point when the DRL contingencies were first imposed. Also, amphetamine did result in stable modification in the temporal spacing of responses. Two aspects of the temporal spacing of responses under amphetamine, as indicated by the IRT per op analysis, are interesting. First of all, the flatter gradient of IRTs per op greater

Table 2

Mean Number of Photobeam Breaks Per 45-Min Session for Each of the 4 Weeks Before and After the Switch in d-Amphetamine Treatment

\begin{tabular}{|c|c|c|c|c|c|c|c|c|c|}
\hline \multirow[b]{3}{*}{ Group } & \multirow[b]{3}{*}{$\mathrm{N}$} & \multicolumn{4}{|c|}{ Before Switch } & \multicolumn{4}{|c|}{ After Switch } \\
\hline & & \multicolumn{8}{|c|}{ Testing Week } \\
\hline & & 1 & 2 & 3 & 4 & 5 & 6 & 7 & 8 \\
\hline $1(\mathrm{~S}-\mathrm{A})$ & 5 & 1243.8 & 1029.8 & 1115.0 & 1012.7 & 2556.4 & 2925.4 & 2786.9 & 3000.7 \\
\hline $2(A-S)$ & 5 & 2887.8 & 3058.6 & 3601.5 & 2771.2 & 1411.0 & 1732.6 & 1416.2 & 1160.3 \\
\hline
\end{tabular}


than $4 \mathrm{sec}$ shows that rats under the influence of amphetamine exhibit less accurate "timing" behavior with or without previous experience and despite prolonged exposure to the DRL contingencies. Also, under the influence of d-amphetamine, the rats always emitted fewer responses after very short IRTs $(0-2 \mathrm{sec})$. This latter result would indicate that d-amphetamine reduces response bursting. Since bursting is usually noted after long IRT delays, this reduction by the d-amphetamine-treated rats suggests that they emitted somewhat fewer long IRTs. However, this was not apparent in terms of their percentages of long IRTs per op. Furthermore, under the amphetamine condition, the rats emitted their highest percentages of very short IRTs when initially exposed to the DRL contingencies, a stage at which they emitted their fewest long IRTs per op. Although the full significance of this greater reduction of very short IRTs under the amphetamine condition is a matter of conjecture at this time, it would appear reasonable to conclude that amphetamine did not result in a simple response perseveration since repetitive responding would be recorded in the 0-2-sec interresponse interval.

\section{REFERENCES}

Carey, R. J. Contrasting effects of increased thirst and septal ablations on DRL responding in rats. Physiology \& Behavior, 1967, 2, 287-290.

Kelleher, R. J., \& Coats, L. Effects of d-amphetamine, meprobamate, phenobarbital, mephenesin or chlorpromazine on DRL and FR schedules of reinforcement with rats. Journal of the Experimental Analysis of Behavior, 1959, 2, 267 (Abstract).

Lal, H. Control of learned conditioned-avoidance responses (CAR) by amphetamine and chlorpromazine. Psychopharmacologia (Berlin), 1969, 14, 33-37.

Laties, V. G., \& Weiss, B. Influence of drugs on behavior controlled by internal and external stimuli. Journal of Pharmacology \& Experimental Therapeutics, 1966, 152, 388-396.

Overton, D. A. Discriminative control of behavior by drug state. Paper presented at the Symposium on Stimulus Properties of Drugs. University of Minnesota, Minneapolis, Minn., 1969.

Reynolds, G. S. A primer of operant conditioning. Glenview, Ill: Scott, Foresman, 1968.

Schuster, C. R., \& Zimmerman, J. Timing behavior during prolonged treatment with d-amphetamine. Journal of the Experimental Analysis of Behavior, 1961, 4, 327-330.

(Received for publication July 20, 1972; revision received August 28, 1972.) 